\title{
Electromechanical Properties of PMN-PT and PZT Ceramics at Cryogenic Temperatures
}

\author{
Mickaël Thiercelin $^{1,2}$, Hichem Dammak ${ }^{1}$ \\ ${ }^{1}$ Ecole Centrale Paris \\ Laboratoire Structures, Propriétés et Modélisation des \\ Solides (SPMS), UMR 8580 CNRS \\ F-92295 Châtenay-Malabry, France \\ mickael.thiercelin@ecp.fr \\ hichem.dammak@ecp.fr
}

\author{
Mai Pham Thi ${ }^{2}$ \\ ${ }^{2}$ Thales Research \& Technology France \\ Laboratoire des Nanocéramiques et Matériaux \\ Multifonctionnels (LNMM) \\ F-91767 Palaiseau, France \\ mai.phamthi@thalesgroup.com
}

\begin{abstract}
Space borne observation requires extremely high resolution systems with large dimensions. The design of such systems implies associating sensing and actuation systems to insure a highly stable positioning of optical components. However, the currently used PZT materials for piezoelectric actuation show strongly diminished strain at cryogenic temperatures. This work explores the performances of PMN-xPT piezoelectric materials at cryogenic temperatures. Temperature dependence of PMN-xPT ceramics is compared with hard PZT (PZT-4) and soft PZT (PZT5H) ceramics from RT to $10 \mathrm{~K}$. PMNPT tetragonal compositions exhibit stable piezoelectric constant in the 250-100 $\mathrm{K}$ range. The highest values of piezoelectric constant are observed for $\mathrm{PMN}-38 \mathrm{PT}$ in the 200-50 K range. All ceramics exhibit decreasing performances versus cooling temperature. This behaviour is attributed to a "freezing out" of extrinsic contributions to piezoelectricity [12] but is also due to a contribution of quantum effects $[13,14]$. The mechanical quality factor $\left(Q_{m}\right)$ increases very quickly from $50 \mathrm{~K}$ to $10 \mathrm{~K}$ for all samples. This fact could be due to low relaxation processes at very low temperatures.
\end{abstract}

Keywords- piezoelectric, cryogenic temperatures, ceramic, PMN-PT, PZT

\section{INTRODUCTION}

Piezoelectric ceramics currently provide the key functional element in devices employed in an exceptionally wide range of applications, including transducers, sensors, signalprocessing and voltage transformers. For several decades, the material of choice for the majority of these applications has been polycrystalline ceramics based on $\mathrm{Pb}\left(\mathrm{Zr}_{1-\mathrm{x}} \mathrm{Ti}_{\mathrm{x}}\right) \mathrm{O}_{3}$ (PZT) due to their unequalled piezoelectric constants and coupling coefficients at room temperature. In space applications, cryogenic actuation is required but the currently used PZT materials do not meet the requirements.

At room temperature, properties of PZT ceramics are optimized using compositions that correspond to the morphotropic phase boundary (MPB). Commercially available "hard" and "soft" PZT compositions exhibit poor piezoelectric performances at temperatures below $100 \mathrm{~K}$. For example, soft PZT has a $\mathrm{k}_{31}$ of about $25 \%$ and a $-\mathrm{d}_{31}$ below $50 \mathrm{pC} / \mathrm{N}$ at $30 \mathrm{~K}$ compared with values of about $35 \%$ and about $250 \mathrm{pC} / \mathrm{N}$, respectively, at room temperature [1]. At $30 \mathrm{~K}$, PZT piezoelectric ceramics do not meet present demands and have only $25 \%$ of their room temperature efficiency [2].

Despite the need for stable actuators at cryogenic temperature, electromechanical properties at very low temperature (below $30 \mathrm{~K}$ ) are rarely reported. In 1983 the dielectric and piezoelectric properties of modified PZT ceramics from $4.2 \mathrm{~K}$ to $300 \mathrm{~K}$ were measured [1]. Properties of perovskite materials from $300 \mathrm{~K}$ to $30 \mathrm{~K}$ were investigated for several compositions of PLZT (La-modified PZT) [3]. Recently, dielectric loss anomalies at low temperatures in PMN-xPT systems were reported [4,5]. Dielectric relaxation and phase transition at cryogenic temperature were also studied [6]. Piezoelectric activity of relaxor-PT ceramics and single crystals at cryogenic temperatures were reported, and the intrinsic and extrinsic contributions were explained [7].

Cryogenic actuators were developed by Xinetic for Nasa application [8]. Multilayer actuators based on electrostrictive materials such as PMN ceramics and PMN-PT single crystals were fabricated and tested [9]. Landolt and Börnstein was used to select materials that exhibited large dielectric constant below $100 \mathrm{~K}$.

The purpose of this work is to complete the previous studies on PMN-xPT ceramics, which were focused on dielectric properties, by investigating the evolution of electromechanical properties from $300 \mathrm{~K}$ to $10 \mathrm{~K}$ in the composition range from $25 \%$ to $42 \%$. Properties of commercial PZT ceramics were also studied in the same conditions.

\section{EXPERIMENTAL PROCEDURE}

Samples of composition (1-x) $\mathrm{Pb}\left(\mathrm{Mg}_{1 / 3} \mathrm{Nb}_{2 / 3}\right) \mathrm{O}_{3}-\mathrm{xpTiO}_{3}$ with $\mathrm{x}=0.25,0.345,0.38,0.42$, (hereafter designated $\mathrm{xPT}$, with $\mathrm{x}$ in \%) were synthesized using the columbite precursor technique [10]. The precursor oxide columbite powder was mixed with $\mathrm{PbO}$ and $\mathrm{TiO}_{2}$ in the appropriate proportions. Each composition was ball-milled for $2 \mathrm{~h}$ in water, and calcined under oxygen at $800^{\circ} \mathrm{C}$ for $4 \mathrm{~h}$ to form the perovskite phase. 
The calcined powders were re-milled and pressed into about $1 \mathrm{~mm}$ thick green-disks. The green-disks were sintered under oxygen at $1140^{\circ} \mathrm{C}$ for $4 \mathrm{~h}$ in an alumina crucible to form densified ceramics ( $d=99.9 \%$ of the theoretical density). In order to compensate the loss during the sintering process, the atmosphere was saturated in $\mathrm{PbO}$. X-ray diffraction patterns recorded with an Inel CPS 120 Detector with $\mathrm{Cu} \mathrm{K} \alpha$ radiation show pure perovskite phases.

The hard PZT4 (TLZ1) and the soft PZT5 (TLZ6) ceramics studied in this work are provided by Thales Underwater Systems Pty Limited (Sydney, Australia). The Curie points of TLZ1 and TLZ6 are $320^{\circ} \mathrm{C}$ and $200^{\circ} \mathrm{C}$, respectively.

Electromechanical properties on transversal (31) mode were recorded on plates. Plates of $8 \times 1 \mathrm{~mm}^{2}$ surface and $1 \mathrm{~mm}$ thickness were machined. Electrodes were deposited by silver pasting onto the surface. The PMN-PT samples were poled by the field cooling method from $180^{\circ} \mathrm{C}$ to $40^{\circ} \mathrm{C}$ with an electric field of $200 \mathrm{~V} / \mathrm{mm}$. The TLZ1 samples were poled at $120^{\circ} \mathrm{C}$ applying an electric field of $2.2 \mathrm{kV} / \mathrm{mm}$. TLZ6 samples were poled by field cooling from $120^{\circ} \mathrm{C}$ to $70^{\circ} \mathrm{C}$ under $2 \mathrm{kV} / \mathrm{mm}$. The electromechanical properties were calculated from the resonance spectra in accordance with the CENELEC standards [11] with the resonance technique using a HP4294A impedance/gain phase analyzer $(40 \mathrm{~Hz}-110 \mathrm{MHz})$. Samples studied in this work were placed in a LHe cryostat from Air Liquid. The temperature can go down from $300 \mathrm{~K}$ to $10 \mathrm{~K}$.

\section{RESUlts}

\section{A. $\mathrm{PMN}-\mathrm{xPT}$}

Fig. 1 and Fig. 2 show the variation of the dielectric constant $\varepsilon_{33}{ }^{\mathrm{T}}$ and of the dielectric loss $(\tan \delta$ ) versus the decreasing temperature. All values diminish and drop at very low temperature for the four PMN-xPT compositions. At 10 $\mathrm{K}$, all samples exhibits a $\varepsilon_{33}{ }^{\mathrm{T}}$ lower than 500 with the highest values for PMN-PT tetragonal composition. $\varepsilon_{33}{ }^{\mathrm{T}}$ is equal to 240, 320, 390, 420 for PMN-25PT, PMN-34.5PT PMN-38PT, PMN-42PT, respectively.

In the RT to $\sim 50 \mathrm{~K}$ temperature range, the variations of the dielectric constant $\varepsilon_{33}{ }^{\mathrm{T}}$ and the dielectric loss $(\tan \delta)$ of PMN$\mathrm{xPT}$ ceramics show different behaviors. For the PMN-25PT

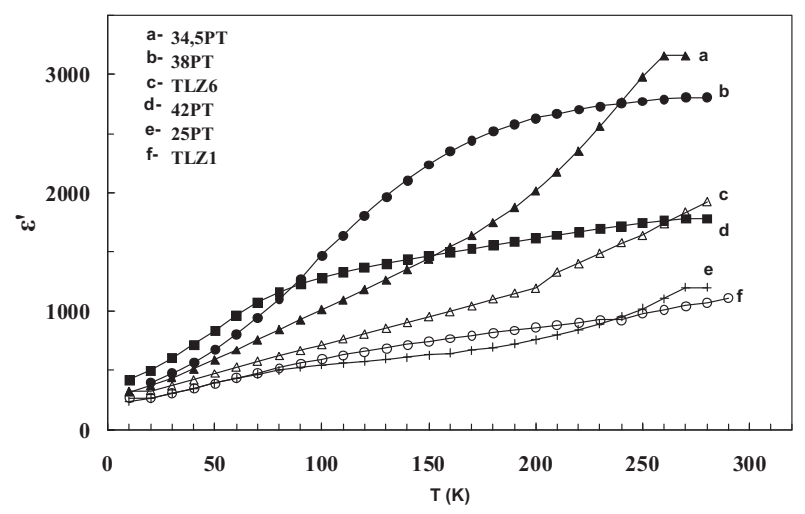

Figure 1. Evolution of the dielectric constant at $1 \mathrm{kHz}$ for PMN-PT and PZT ceramics, as a function of the temperature from $300 \mathrm{~K}$ to $10 \mathrm{~K}$.

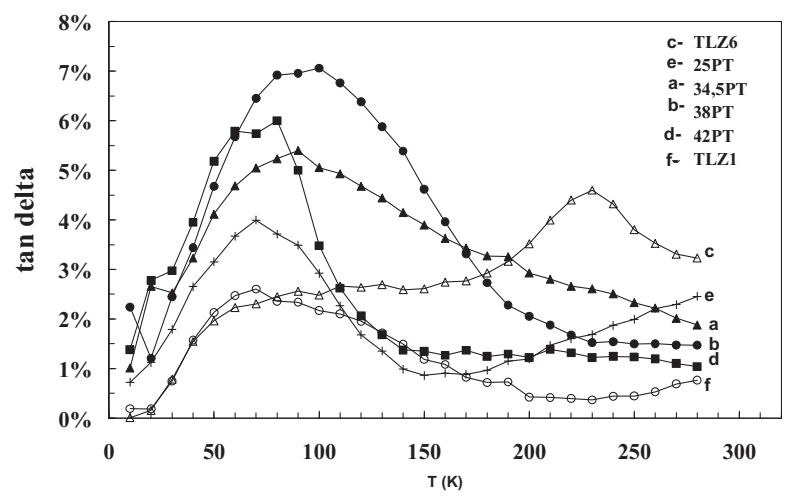

Figure 2. Temperature dependence of the dielectric losses for PMN-PT and PZT ceramics, as a function of the temperature from $300 \mathrm{~K}$ to $10 \mathrm{~K}$.

ceramic exhibiting pure rhomboedral structure, as shown on the Fig. 1e, the decrease of the dielectric constant is moderate. The dielectric curve shows a slope change near $70 \mathrm{~K}$. The same behaviour was observed for the pure PMN-42PT tetragonal composition PMN-42PT. The dielectric constant shows a slight decrease between RT to $80 \mathrm{~K}$ and then a stronger decrease with decreasing temperature (Fig. 1d).

For the other two compositions in the tetragonal structure near morphotropic phase boundary $(\mathrm{x}=0.38)$ and in the MPB $(\mathrm{x}=0.345)$, the behaviour of the materials is different. Indeed, the PMN-38PT composition exhibits high value and relative stability of the dielectric constant from $300 \mathrm{~K}$ to $200 \mathrm{~K}$ and then decreases strongly when the temperature is lowered down to $10 \mathrm{~K}$ (Fig. 1b). For the composition in the MPB (PMN34.5PT), the dielectric constant decreases quickly with cooling temperature (Fig. 1a).

As reported by Singh [15] and Ragini [16], the low temperature transitions involving two ferroelectric phases could not give rise to prominent anomalies in dielectric constant curve while the temperature dependence of elastic modulus $\left(\mathrm{s}_{31}\right)$ or piezoelectric resonance frequency clearly exhibit transitions.

Fig. 3 presents the variation of the resonance frequency, $f_{m}$, with temperature from $500 \mathrm{~K}$ to $10 \mathrm{~K}$ for PMN-xPT ceramics. These data complete those reported up to $150 \mathrm{~K}$ by Singh [15]. Ferroelectric-paraelectric transition leads to sudden drop of

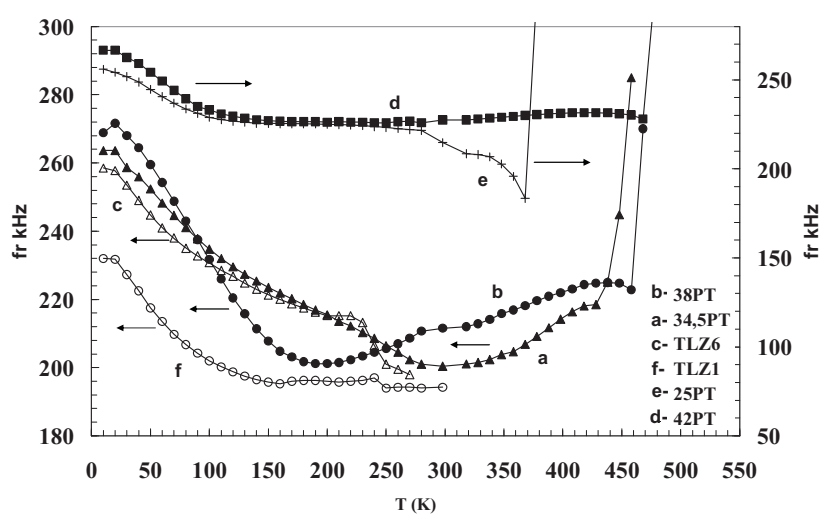

Figure 3. The resonance frequency for PMN-xPT and PZT ceramics, as a function of the temperature from $300 \mathrm{~K}$ to $10 \mathrm{~K}$. The curves $\mathrm{d}$ and $\mathrm{e}(\mathrm{x}=0.25$ $\& 0.42)$ are in the right axis. The curves $\mathrm{a}, \mathrm{b}, \mathrm{c}$ and $\mathrm{f}$ are in the left axis. 
resonance frequency at $378 \mathrm{~K}, 458 \mathrm{~K}, 468 \mathrm{~K}$ and $478 \mathrm{~K}$, respectively. The values, close to the Tmax, are consistent with the Vegard law, which increases with the increasing PT content. PMN-xPT ceramics compositions show a Tmax at $385 \mathrm{~K}, 435 \mathrm{~K}, 455 \mathrm{~K}$, and $500 \mathrm{~K}$ for $\mathrm{x}=0.25,0.345,0.38$, and 0.42 , respectively.

At temperatures below $300 \mathrm{~K}$, compositions of $\mathrm{x}=0.25$ and 0.42 show a behaviour like normal solids for which the elastic modulus $\left(\mathrm{s}_{i j}\right)$, and hence resonance frequency $f_{r}\left(f_{r} \propto\left(s_{i j}^{-1 / 2}\right)\right.$, is expected to increase on cooling from higher temperature side. For both, variation of $f_{r}$ show a clear changing slope near 70 $K$ and another one near $300 \mathrm{~K}$ for $\mathrm{x}=0.25$. For the two other compositions $\left(\mathrm{x}=0.38\right.$ and 0.345), $f_{r}$ decreases with decreasing temperature, showing a minimum around $160 \mathrm{~K}$ and $300 \mathrm{~K}$. The fact reveals lattice instability due to a soft mode near structural phase transition [16]. This clearly indicates a phase transition from the room temperature tetragonal phase to monoclinic phase for $x=0.38$ and from monoclinic $\mathrm{M}_{\mathrm{A}}$ to monoclinic $\mathrm{M}_{\mathrm{C}}$ for $x=0.34$.

For two other compositions $(x=0.25$ and 0.42$)$, show behaviour like normal solids for which, the elastic modulus, and hence $f_{m}$, is expected to increase on cooling from higher temperature side. For both, variation of $f_{m}$ show a clear slope change near $70 \mathrm{~K}$ and another one near $300 \mathrm{~K}$ for the former. The slope change at $300 \mathrm{~K}$, observed for $\mathrm{x}=0.25$ would be related to phase transition from rhombohedra to monoclinic structure [15].

Concerning the dielectric loss variation (Fig. 2), the 0.25 composition shows a decrease from RT down to $160 \mathrm{~K}$ then start to an increase to reach a maximum near $70 \mathrm{~K}$. The 0.42 composition shows the same strong peak near $70 \mathrm{~K}$, while the other compositions ( $\mathrm{x}=0.38$ and 0.345$)$ exhibit much larger and stronger peaks centered near $100 \mathrm{~K}$.

The temperature dependence of the coupling efficiency and the piezoelectric constant, presented on Fig. 4, show the same variation as the dielectric constant. The piezoelectric constant $\left(\mathrm{d}_{31}\right)$ decreases moderately for $\mathrm{x}=0.25$ and rapidly for $\mathrm{x}=$ 0.345 when the temperature decrease from RT to $10 \mathrm{~K}$. For $\mathrm{x}$ $=0.38$ and 0.42 , the piezoelectric constants are stable between RT and about $120 \mathrm{~K}$ and $80 \mathrm{~K}$, respectively, before dropping at $10 \mathrm{~K}$, down to a value of $\mathrm{d}_{31}$ equal to $30 \mathrm{pC} / \mathrm{N}$ for both.

\section{B. PZT}

The temperature dependence of the piezoelectric coefficient and the dielectric constant of PZT ceramics are shown on fig 1-4. The piezoelectric constants are listed on the table I.

The same behaviour as PMN-xPT was observed. The dielectric constant decreases from RT to $10 \mathrm{~K}$ but the slopes are different for the soft and the hard PZT. Hard PZT ceramic presents moderate variations (Fig. 1f) while soft PZT ceramic shows strong decrease (Fig. 1c). The dielectric loss values are lower than those of PMN-PT ceramics (Fig. 2). Indeed, for the
TLZ6 soft ceramic, the losses are above to $3 \%$ at room temperature, and below at $2 \%$ at $50 \mathrm{~K}$ and then very low $(0.01 \%)$ at $10 \mathrm{~K}$. For the TLZ1 hard ceramic, the losses, very low at room temperature $(0.76 \%)$, increase up to a maximum at $60 \mathrm{~K}(2.5 \%)$ and then decrease down to a very low value $(0.19 \%)$. The maximum of dielectric loss peaks (Fig. 3c, 3f) are also lower than that of PMN-PT ceramics.

The temperature dependence of the piezoelectric coefficient $\mathrm{d}_{31}$ is very similar to that of the dielectric constant except for the decrease from room temperature to $10 \mathrm{~K}$. TLZ1 and TLZ6 have a good coupling coefficient of about $37 \%$ at room temperature, $22 \%$ at $10 \mathrm{~K}, 33 \%$ at $\mathrm{RT}$ and $22 \%$ at $10 \mathrm{~K}$ respectively. The $\mathrm{k}_{31}$ is relatively stable and, at a temperature of about $50 \mathrm{~K}$, the value diminishes.

\section{DISCUSSION AND CONCLUSION}

Dielectric and electromechanical properties of piezoelectric ceramics diminish when the temperature decreases. On lowering the temperature down to near $150 \mathrm{~K}$, the decrease may be due to the sequence tetragonal-monoclinic $M_{C}$ monoclinic $\mathrm{M}_{\mathrm{B}}$ transitions and a long range monoclinic order [15].

At very low temperature, the behavior could be due to a "freezing out" of extrinsic contributions (i.e., ferroelectric domains wall motion) to piezoelectricity [12] and probably also due to a quenched chemical disorder and polar nanoregions. Polar nanoregions (PNRs) with a size of $60 \AA$ and chemically ordered regions of $\mathrm{Mg}^{2+}$ and $\mathrm{Nb}^{5+}$ with a size of $20 \AA$, were reported [17] for pure PMN and PMN-6PT relaxor compositions, while any super lattice structures were observed for higher PT contents. The substitution of $\mathrm{Ti}^{4+}$ in PMN-xPT suppresses the chemically ordered regions and enhances the size of PNRs.

On the other hand, the thermal conductivity [17] of ferroelectric $\mathrm{PbTiO}_{3}$ shows a peak at $65 \mathrm{~K}$ while that of relaxor PMN exhibits a broader incident near $10 \mathrm{~K}$ and plateau near $100 \mathrm{~K}$. The behaviors are typical of crystalline dielectric solids for $\mathrm{PbTiO}_{3}$ and glasslike amorphous materials, which is attributed to the presence of polar nanoregions for PMN. PMN-PTs, behave like PMNs, are partially crystallized glasses and this suggests enhanced elastic mismatch arising from the coexistence of PNRs and mesoscopic ferroelectric domains.

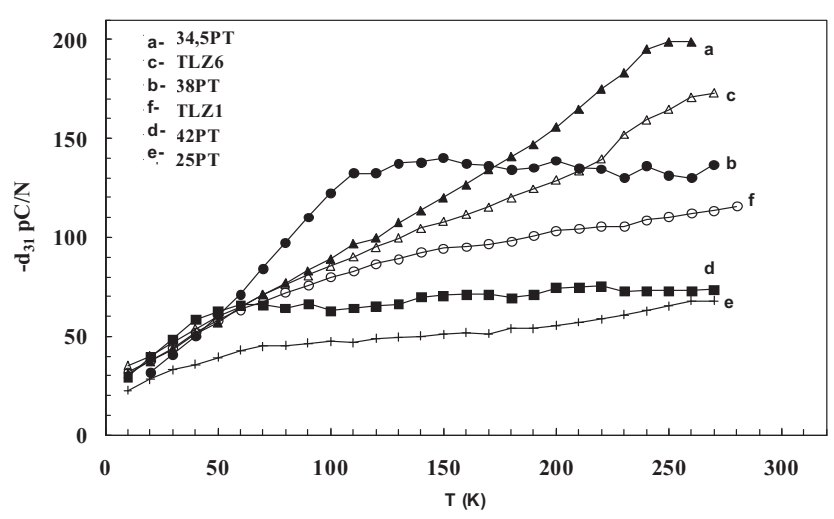

Figure 4. Temperature dependence of the piezoelectric coefficient $-\mathrm{d}_{31}$. of PMN-xPT and PZT ceramics. 
TABLE I. PIEZOELECTRIC PROPERTIES FOR PMN-PT AND PZT

\begin{tabular}{|c|c|c|c|c|c|c|c|c|c|}
\hline & \multicolumn{3}{|c|}{$\varepsilon_{33}^{\mathrm{T}}$} & \multicolumn{3}{|c|}{$-d_{31}(p C / N)$} & \multicolumn{3}{|c|}{$k_{31}(\%)$} \\
\hline & RT & $100 \mathrm{~K}$ & $20 \mathrm{~K}$ & RT & $100 \mathrm{~K}$ & $20 \mathrm{~K}$ & RT & $100 \mathrm{~K}$ & $20 \mathrm{~K}$ \\
\hline PMN-42PT & 1781 & 1280 & 501 & 74 & 63 & 39 & 19.5 & 21.2 & 10 \\
\hline PMN-38PT & 2800 & 1470 & 397 & 140 & 122 & 32 & 24 & 27.5 & 11 \\
\hline $\begin{array}{l}\text { PMN- } \\
34.5 \mathrm{PT}\end{array}$ & 3200 & 1010 & 373 & 200 & 89 & 37 & 34 & 28 & 17 \\
\hline PMN-25PT & 1200 & 545 & 263 & 68 & 47 & 28 & 22 & 22.7 & 15.5 \\
\hline $\begin{array}{l}\text { TLZ1 } \\
\text { (PZT4) }\end{array}$ & 1110 & 595 & 270 & 116 & 80 & 35 & 32.7 & 31 & 22 \\
\hline $\begin{array}{l}\text { TLZ6 } \\
\text { (PZT5) }\end{array}$ & 2000 & 715 & 327 & 173 & 89 & 40 & 36.5 & 32 & 23 \\
\hline
\end{tabular}

This thermal conductivity peak of PT at $65 \mathrm{~K}$ [17] could be related to the strong incident observed in dielectric loss variations of PMN-xPT ( $70 \mathrm{~K}$ and $100 \mathrm{~K}$ ) observed on this work. The dielectric loss peaks are also consistent with the slope change near $70 \mathrm{~K}$ for that the quality factors increase very quickly [18] i.e. the mechanical losses exhibit strong decrease near $70 \mathrm{~K}$. Further studies are necessary to clarify the behavior.

The dielectric constant coefficient $\varepsilon_{33}{ }^{\mathrm{T}}$, the piezoelectric coefficient $\mathrm{d}_{31}$ and the coupling factor coefficient $\mathrm{k}_{31}$ of PMN$\mathrm{PT}$ at $100 \mathrm{~K}$ and $20 \mathrm{~K}$ are listed in table I.

PZT and PMN-xPT present nearly the same piezoelectric performances at very low temperatures $(20 \mathrm{~K})$. At low temperatures, the tetragonal phase PMN-38PT shows better performances with relatively stability from $300 \mathrm{~K}$ to $100 \mathrm{~K}$.

Further studies are in progress by doping tetragonal PMNPT compositions both in ceramic and single crystal.

\section{REFERENCES}

[1] X. L. ZHANG, Z. X. CHEN, L. E. CROSS and W. A. SCHUlZE, J. Mater.Sci., Vol. 18, pp. 968, 1983.

[2] Z.Q. Zhuang, M.J. Haun, S.J. Jang, L.E. Cross, , IEEE, pp. 968-972, 1986.
[3] D.S Paik, S.E Park and T.R. Shrout, J. Mater. Sc., Vol. 34, pp. 469-473, 1999.

[4] Zhenrong $\mathrm{Li}$, Zhuo Xu, Zengzhe Xi, Linhong Cao, Xi Yao, J. Electroceram., Vol. 21, pp. 279-282, 2008.

[5] M.H. Lente, A.L. Zanin, E.R.M. Andreeta, I.A. Santos, D. Garcia, J.A. Eiras, Appl. Phys. Lett., Vol. 85(6), pp. 982, 2004.

[6] S.P. Singh, A.K. Singh, D. Pandey, S.M. Yusuf, Phys. Rev. B, Vol. 76, 054102, 2007

[7] F. Li, S. Zhang, Z. Xu, X. Wei, J. Luon, T.R. Shrout, Appl. Phys. Lett., Vol. 96, 192903, 2010.

[8] M.L. Mulvihill, R.J. Shawgo, R. B. Bagwell, M.A. Ealey, J. of Electroceram., Vol. 8, pp. 121-128, 2002.

[9] K.H. Hellwege and A.M. Hellwege (Eds.), Landolt-Börnstein: (Springer-Verlag, Berlin Heidelberg New York, 1981), Vol.16, p.283

[10] S.L. Swartz and T.R. Shrout, Mater. Res. Bull., Vol. 17, pp. 1245, 1982.

[11] CENELEC, NF EN 50324-1, pp. 13-15, 2002.

[12] R. GERSON, J. Appl. Phys., Vol. 33, pp. 830, 1962.

[13] M. Tachibana, E. Takayama-Muromachi, Phys. Rev. B, Vol. 79, 100104(R), 2009.

[14] M. Tachibana, K. Sasame, H. Kawaji, T. Atake, E. TakayamaMuromachi, Phys. Rev. B, Vol. 80, 094115, 2009.

[15] A.Kumar Singh, D. Pandey, O. Zaharko, Phys. Rev. B, Vol. 74, 024101, 2006.

[16] Ragini, S. K. Mishra, D. Pandey, H. Lemmens, and G. Van Tendeloo, Phys. Rev. B, Vol. 64, 054101, 2001.

[17] M. Tachibana, T. Kolodiazhnyi, and E. Takayama-Muromachi, Appl. Phys. Lett. 93, 092902, 2008.

[18] M. Thiercelin, Thales Research \& Technology private report, 2010. 